\title{
Investigation of Some Corticosteroids as Glutathione Reductase Inhibitor
}

\author{
Esra Şentürk (i) 1,*, Murat Şentürk (i)2
}

${ }^{1}$ School of Health Services, Agri Ibrahim Cecen University, Agri, Turkey

${ }^{2}$ Faculty of Pharmacy, Agri Ibrahim Cecen University, Agri, Turkey

\begin{abstract}
The detection of glutathione reductase inhibitors (GRIs) has recently become very popular due to their use as malarial and cancer drugs. Today, steroidal compounds have several clinical roles due to their potent immunomodulating and anti-inflammatory properties. In this study, GR inhibitory capacity of some corticosteroids (dexamethasone, prednisolone and methylprednisolone) has been reported. Amongst these steroidal molecules dexamethasone showed the weakest inhibitory effect on GR enzyme. $\mathrm{IC}_{50}$ values were determined by drawing \% activity-[I] graphs for these corticosteroids showing inhibition effects. These corticosteroids have inhibition ranging micromolar for $\mathrm{GR}$ with $\mathrm{IC}_{50}$ values. These corticosteroids exhibit very potent inhibitory activity against GR enzyme at low micromolar concentrations when compared to well-known GRIs.
\end{abstract}

\section{ARTICLE HISTORY}

Received: February 25, 2020

Revised: April 02, 2020

Accepted: May 09, 2020

\section{KEYWORDS}

Steroid,

Glutathione reductase,

Inhibition,

Oxidative stress,

Cancer

\section{INTRODUCTION}

Glutathione reductase (EC 1.6.4.2, GR) is a homodimeric enzyme with flavin adenine dinucleotide (FAD) as a prosthetic group in its active site. This enzyme catalyzes the conversion of oxidized glutathione (GSSG) to reduced glutathione (GSH) using nicotinamide adenine dinucleotide phosphate (NADPH) molecules. GR is involved in balancing the intracellular redox system. For the GR enzyme, both GSSG and NADPH, analogs of their substrates, and complexes containing many different ligands have been investigated in detail by the enzyme's high-resolution crystal structures [1-3]. It has been reported that the glutathione reductase enzyme from Baker's yeast (Saccharomyces cerevisiae) shows 50\% similarity to Escherichia coli $(E$. coli) and human GRs and all of them exhibit well-preserved secondary structural elements $[3,4]$. Inhibition of the GR enzyme has been studied using many different compounds. As a result of these trials, it was observed that there was a decrease in GSH / GSSG ratio and an increase in $\mathrm{NAD}(\mathrm{P}) \mathrm{H} / \mathrm{NAD}(\mathrm{P})^{+}$ratio [4-6]. In some studies, it has been determined that the inhibition of the GR enzyme does not affect the production of free radicals or the expression of other enzymes involved in GSH biosynthesis [6-8]. However, the strong activity of the GR enzyme in cancer cells helps to provide resistance to various chemotherapeutic drugs. High intracellular GSH levels provide an advantage for tumor cells to survive, especially in lung,

CONTACT: Esra Şentürk $\square$ ecavusoglu@agri.edu.tr $\equiv$ School of Health Services, Agri Ibrahim Cecen University, Agri, Turkey 
breast, larynx, colon and bone marrow cancers [7,8]. Considering this situation, it can be seen that substances that inhibit the GR enzyme can be used for anticancer treatment.

The term steroid is used for a wide variety of molecules with different physiological effects. More specifically, corticosteroids are a class of chemical that are both synthesized in the lab and have naturally produced hormonal effects. Glucocorticoids usually regulate metabolism and inflammation. Mineralocorticoids regulate sodium and water levels. Corticosteroids are in a spectrum ranging from glucocorticoid effects to only mineracocorticoid effects, and steroid compounds are selected based on their suitability to a particular treatment [9]. Many clinical roles of steroid molecules have been associated with potent antiinflammatory and immunomodulatory properties [10]. Dexamethasone, prednisolone and methylprednisolone are synthetic corticoids. All three are used as medicines for many diseases, especially anti-inflammatory therapy (Table 1).

Table 1. Substances tested, medical usage and molecular structures.

\begin{tabular}{|c|c|c|}
\hline Compound & Medical usage & Molecular structure \\
\hline Dexamethasone & $\begin{array}{l}\text { Inflammation, Rheumatoid } \\
\text { arthritis }\end{array}$ & \\
\hline Prednisolone & $\begin{array}{l}\text { Ulcerative colitis, Asthma, } \\
\text { Crohn's disease, Rheumatoid } \\
\text { arthritis }\end{array}$ & \\
\hline Methylprednisolone & $\begin{array}{l}\text { Arthritis, } \\
\text { inflammation }\end{array}$ & \\
\hline
\end{tabular}

In this study, the GR enzyme inhibitory potential of some corticosteroids (dexamethasone, prednisolone and methylprednisolone) was tried to be determined. For this purpose, both in silico (docking) and in vitro experiments were carried out.

\section{MATERIAL and METHODS}

\subsection{Measurement of Glutathione Reductase Activity}

GR enzyme activity was performed according to the Beutler method [11]. In order to determine the activity of GR enzyme from baker's yeast, the decrease of NADPH in the presence of the substrate GSSG (oxidized glutathione) was done by spectrophotometrically at $340 \mathrm{~nm}$ under the assay condition at $25^{\circ} \mathrm{C}, 100 \mathrm{mM}$ Tris- $\mathrm{HCl}$ buffer $\mathrm{pH} 8.0$ [5].

\subsection{Inhibition Studies}

First, 1mg of each corticosteroid was dissolved in $1 \mathrm{~mL}$ DMSO and then diluted to various concentrations with pure water. To determine GR inhibition activity, five serial dilutions of the inhibitors were measured. The reaction system was composed of 5-30 $\mu \mathrm{L}$ inhibitor sample, 200 $\mu \mathrm{L}$ buffer $(0.1 \mathrm{M}, \mathrm{pH}$ 8.0: Tris-HCl), 660-695 $\mu \mathrm{L}$ pure water, $50 \mu \mathrm{L}$ GSSG, $50 \mu \mathrm{L}$ NADPH and $10 \mu \mathrm{L}$ enzyme $(0.3$ units $/ \mathrm{mL})$. The reaction was initiated upon addition of the enzyme. The reaction system was prepared at room temperature in a quartz cuvette. The blank reading was composed of all chemicals except the inhibitor. The absorbance of the reaction mixture was 
measured at $340 \mathrm{~nm}$ within 3 minutes from the start of the reaction on a Thermo Scientific Evolution 200 Series UV-VIS spectrophotometer. The absorbance for each reaction mixture was measured three times within 3 minutes of adding the enzyme, and the results were reported as mean \pm standard deviation. The inhibition properties are reported as $\mathrm{IC}_{50}$ values that were determined graphically from inhibition curves of log inhibitor concentration versus percent of inhibition. $\mathrm{IC}_{50}$ values represent the concentration of inhibitor required for $50 \%$ inhibition of the enzyme.

\subsection{In silico Studies}

In silico placement studies were conducted to investigate interactions between ligand (corticosteroid substance) and amino acid residues around the active site of the GR enzyme (PDB: 1DNC). In silico docking figures and values are taken from Swissdock (Figure 1 and Table 2).

\section{RESULTS and DISCUSSION}

GR, which is an antioxidant enzyme, performs a very important task by performing the regulation of GSH in the redox metabolism in the cells of many living things. It is involved in the formation of deoxyribonucleotides in GSH redox hemostasis. The viability of fastproliferating cells and cells that are resistant to oxidative stress is relatively dependent on the regeneration of GSH. Therefore, potential GR inhibitors play an important role in the development of antitumor and antiparasitic drugs [2,12,13]. In this study, we demonstrated the in vitro inhibitory effects of prednisolone, methylprednisolone and dexamethasone corticosteroid drugs on the GR enzyme. These corticosteroid drugs were found to be highly potent inhibitors of GR enzyme at submicromolar level as shown in the Table 1 . The $\mathrm{IC}_{50}(\mu \mathrm{M})$ values of the compounds was determined as $0.0116,0.0210$ and 0.0352 for prednisolone, methylprednisolone and dexamethasone, respectively. For carmustine (N, N-bis (2-chloroethyl) -N-nitro) known as a strong and specific GR inhibitor, the $\mathrm{IC}_{50}$ value for the same enzyme was obtained as $647 \mu \mathrm{M}$ [14]. When the $\mathrm{IC}_{50}$ values we obtained for the corticosteroids we used in our study were compared with carmustine; Approximately 55.77 times prednisolone, methylprednisolone 30.8 times and dexamethasone 18.38 times lower show the same effect. In experiments performed on GR enzyme by Grellier et al., [15] it was determined that nitro aromatic substances containing quinoline ring affect GR enzyme. Therefore, it has been reported that it can be used as antistimulants and anticancer drugs [15]. In studies conducted by different research groups on GR enzymes isolated from different sources, some drugs and chemicals containing different functional groups were found to have an inhibition effect [1419]. The aim of these studies in the literature and our study is the same, to identify new drug molecules in which GR inhibitors can be used in treatment (primarily diseases such as cancer and malaria). For this purpose, there are two major advantages of trying substances previously used as drugs. The first is that there is no need to conduct very costly and time consuming human cytotoxicity experiments. The second is that the production system already exists.

We also made in silico studies of these three corticosteroid drugs, which we determined to be effective GR enzyme inhibitors. Prediction binding models between these three molecules and GR enzyme we obtained from PDB through Swisdock program were created. For this purpose, the fully flexible placement methodology of these ligands and the estimated $\Delta \mathrm{G}$ values and binding models were determined by Swissdock on the simulation of protein residues of the GR enzyme. Prednisolone was placed in the binding site of methylprednisolone and dexamethasone GR enzyme. Estimated $\Delta \mathrm{G}$ scores and corresponding binding interactions of fixed inhibitors in GR targets are shown in Table 2. In addition, docking models for three corticosteroids with GR enzyme are shown in Figure 1. In addition to these data, the graphs we 
use to determine $\mathrm{IC}_{50}$ values experimentally for three corticosteroids with GR enzyme are shown in Figure 2.

Table 2. Inhibition values and docking scores for the enzyme GR used in the research.

\begin{tabular}{lcc}
\hline Inhibitor & $\mathrm{GR} \mathrm{IC}_{50}(\mu \mathrm{M})^{*}$ & Estimated $\Delta \mathrm{G}, \mathrm{kcal} / \mathrm{mol}$ \\
\hline Prednisolone & $0.0116 \pm 0.0002$ & -7.42 \\
Methylprednisolone & $0.0210 \pm 0.0005$ & -7.23 \\
Dexamethasone & $0.0352 \pm 0.0017$ & -7.02 \\
Carmustine $^{\mathrm{a}}$ & 647.00 & - \\
\hline
\end{tabular}

* Mean from at least three determinations. ${ }^{\text {aRef }}[19]$.
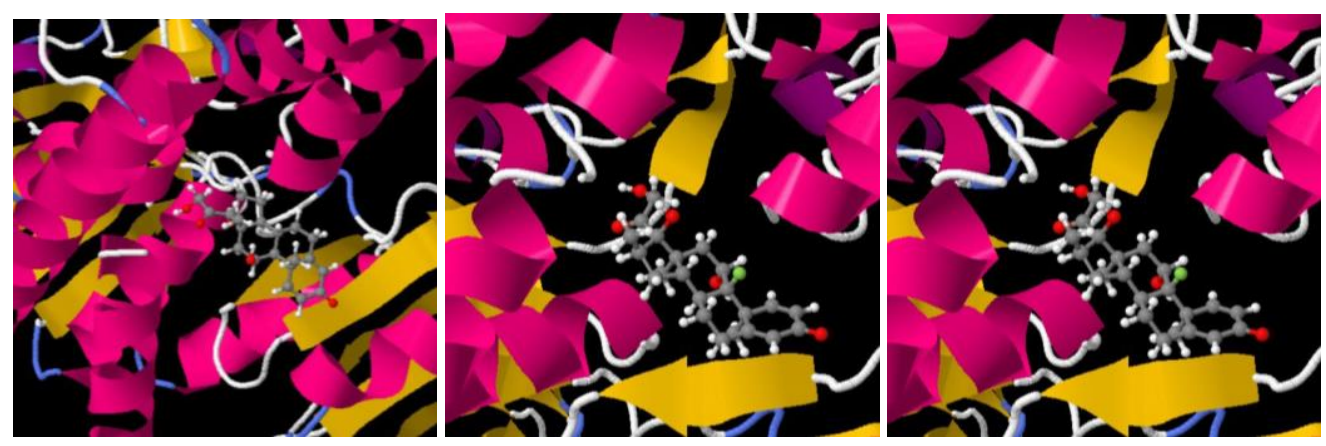

Figure 1. 3D docking binding models of prednisolone, methylprednisolone and dexamethasone with GR enzyme, respectively.
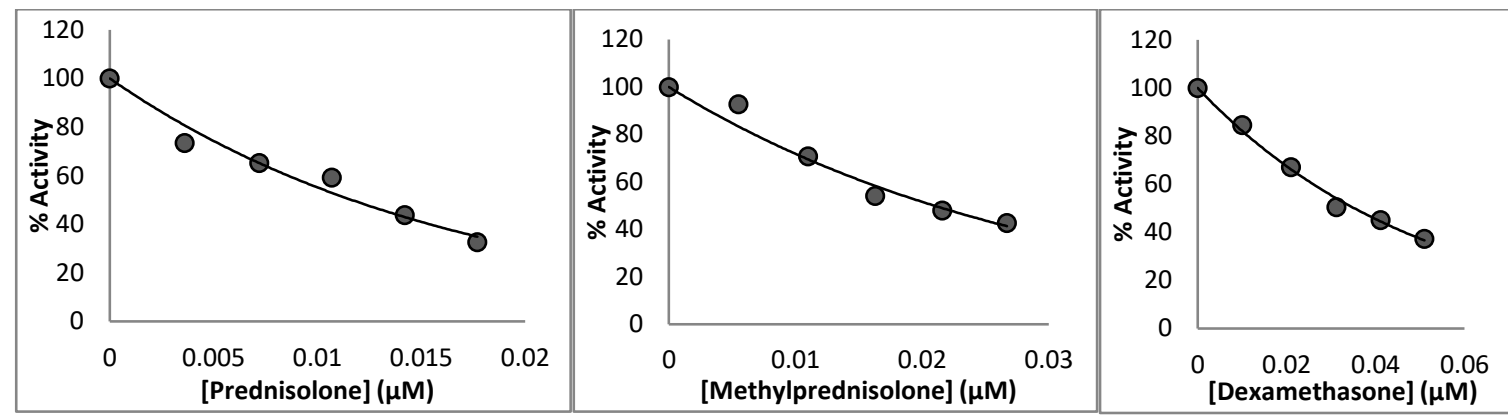

Figure 2. $\mathrm{IC}_{50}$ inhibition graph of GR enzyme with prednisolone, methylprednisolone and dexamethasone, respectively.

Medicines are molecules used to treat or prevent diseases. In recent years, both pharmaceutical companies and scientists have been extensively investigating whether drug molecules are used outside of the diseases in which they are used for treatment. This is done because the time to register a new molecule as a medicine is very long and expensive. A standardized production process in a molecule used as a drug and the completion of all phase studies provide an important advantage. In this reported study, the inhibition effects of three different corticosteroid drugs on GR enzyme were tried and also docking studies with human GR enzyme were done and shown in Figure 1, Figure 2 and Table 2. When the values obtained in Table 2 are examined, it is seen that both experimental and theoretical data are compatible for GR enzyme. In our study, it was found that the most effective GR inhibitor from the corticosteroids tested was prednisolone and the placement score supported this. When these findings were compared with literature [15-18], it was determined that these three corticosteroids we tried were very effective GR inhibitors. In the literature, both known as a strong GR inhibitor ( $\mathrm{IC}_{50}: 647 \mu \mathrm{M}$ ) and used as a cancer drug, carmustine has high toxicity and causes inhibition of human DNA synthesis, causing various side effects [19]. The GR enzyme 
plays a critical role in thiol homeostasis, maintaining a high GSH / GSSG ratio [20]. Although physiologically essential, the human cellular GSH pool can also increase tumor formation and resistance to anticancer drugs. It is also seen as the target enzyme in the treatment of viral infections such as malaria and HIV [21]. Here we report these three corticosteroids that we use in our study as potent GR inhibitors. The $\mathrm{IC}_{50}$ values of these corticosteroids were found to be 18.38 to 55.77 times lower than the carmustine we used as positive control, so these compounds were considered to be potent GR enzyme inhibitors.

\section{CONCLUSION}

Resistance in the use of cancer drugs is the most important reason for failure in the treatment of cancer. Many cancer drugs induce the production of intracellular reactive oxygen species (ROS) as part of their mechanism of action. Resistance to such drugs develops by increasing the level of intracellular GSH of the cancer cell. Increasing intracellular oxidative stress increases the sensitivity of cancer cells to anticancer drugs. GR inhibition is a new approach that can be used in cancer treatment. GR enzyme inhibitors are similarly seen as the target enzyme in the treatment of viral infections such as malaria and HIV by increasing the intracellular oxidative stress level of the host cell. Here we report these three corticosteroid drugs (prednisolone, methylprednisolone and dexamethasone) that we found to be potent GR inhibitors in our study. Strong enzyme inhibitors can have inhibitory effects even at very low concentrations. Therefore, it is thought that their toxicity and, therefore, their side effects will be less. It showed a very strong inhibitory effect against GR for corticosteroid drugs used in this study. Blockade of GR occurs as an atherapic method to treat various oncological diseases or some viral infections. These results indicate that these corticosteroids have the potential to be used in the treatment of cancer or some viral infections, but should be confirmed by in vivo and/or clinical trials for more precise results.

\section{Acknowledgements}

This work study was presented as a summary in the 3rd International Conference on Advances in Natural and Applied Sciences (ICANAS 2018), 2018, Antalya, Turkey. Authors gratefully thanks to Swissdock for in silico data. The authors gratefully acknowledge the financial support from the AİÇÜ Scientific Research Council (ECZF.19.001).

\section{Declaration of Conflicting Interests and Ethics}

The authors declare no conflict of interest. This research study complies with research publishing ethics. The scientific and legal responsibility for manuscripts published in IJSM belongs to the authors.

\section{Orcid}

Esra Şentürk (iD) https://orcid.org/0000-0003-4378-7678

Murat Şentürk (D) https://orcid.org/0000-0002-9638-2896

\section{REFERENCES}

[1]. Karplus, P.A., Schulz, G.E. (1987). Refined structure of glutathione reductase at 1.54 A resolution. J. Mol. Biol., 195, 701-729. doi:https://doi.org/10.1016/0022-2836(87)90194

[2]. Karplus, P.A., Pai, E.F., Schulz, G.E. (1989). A crystallographic study of the glutathione binding site of glutathione reductase at $0.3 \mathrm{~nm}$ resolution. Eur. J. Biochem., 178, 693-703. doi:https://doi.org/10.1111/j.1432-1033.1989.tb14500.x

[3]. Kocaoglu, E., Talaz, O., Cavdar, H., Senturk, M., Supuran, C.T., Ekinci, D. (2019). Determination of the inhibitory effects of $\mathrm{N}$-methylpyrrole derivatives on glutathione 
reductase enzyme. J. Enzym. Inhib. Med. Chem., 34, 51-54. doi:https://doi.org/10.1080/ 14756366.2018 .1520228

[4]. Yu, J., Zhou, C.Z. (2007). Crystal structure of glutathione reductase Glr1 from the yeast Saccharomyces cerevisiae. Proteins, 68, 972-979. doi:https://doi.org/10.1002/prot.21354

[5]. Balaydin, H.T., Ozil, M., Senturk, M. (2018). Synthesis and glutathione reductase inhibitory properties of 5-methyl-2,4-dihydro-3H-1,2,4-triazol-3-one's aryl schiff base derivatives. Archive der Pharm., 351, e1800086. doi:10.1002/ardp.201800086

[6]. Couto, N., Wood, J., Barber, J. (2016). The role of glutathione reductase and related enzymes on cellular redox homoeostasis network. Free Rad. Biol. Med., 95, 27-42. doi:https://doi.org/10.1016/j.freeradbiomed.2016.02.028

[7]. Balendiran, G.K., Dabur, R., Fraser, D. (2004). The role of glutathione in cancer. Cell Biochem. Funct., 22, 343-352. doi:10.1002/cbf.1149

[8]. Traverso, N., Ricciarelli, R., Nitti, M., Marengo, B., Furfaro, A.L., Pronzato, M.A., Marinari, U.M., Domenicotti, C. (2013). Role of glutathione in cancer progression and chemoresistance. Oxid. Med. Cell. Longev., 2013. doi:https://doi.org/10.1155/2013/9729 13

[9]. Williams, D.M. (2018). Clinical pharmacology of corticosteroids. Respir Care, 63, 655670. doi:https://doi.org/10.4187/respcare.06314

[10]. Stewart, P.M., Krone, N.P. (2011). The adrenal cortex. In: Melmed, S., Polonsky, K., Larsen, P.R., Kronenberg, H. eds. Williams Textbook of Endocrinology. 12th ed. Philadelphia, PA: Saunders-USA. ISBN: 9781437703245.

[11]. Beutler, E. (1984). Red Cell Metabolism. A Manual of Biochemical Methods. Grune and Stratton Inc, Orlando. ISBN: 08089167269780808916727.

[12]. Boehme, C.C., Arscott, L.D., Becker, K., Schirmer, R.H., Williams, C.H. (2000). Kinetic characterization of glutathione reductase from the malarial parasite Plasmodium falciparum comparison with the human enzyme. J. Biol. Chem., 275, 37317-37323. doi:10.1074/jbc.M007695200

[13]. Becker, K., Rahlfs, S., Nickel, C., Schirmer, R.H. (2003). Glutathione-function and metabolism in the malarial parasite Plasmodium falciparum. Biol. Chem., 384, 551-566. doi:https://doi.org/10.1515/BC.2003.063

[14]. Seefeldt, T., Zhao, Y., Chen, W., Raza, A.S., Carlson, L., Herman, J., Stoebner, A., Hanson, S., Foll, R., Guan, X.M. (2009). Characterization of a novel dithiocarbamate glutathione reductase inhibitor and its use as a tool to modulate intracellular glutathione. J Biol Chem., 284, 2729-2737. doi:10.1074/jbc.M802683200

[15]. Grellier, P., Sarlauskas, J., Anusevicius, Z., Maroziene, A., Houee-Levin, C., Schrevel, J., Cenas, N. (2001). Antiplasmodial activity of nitroaromatic and quinoidal compounds: Redox potential vs inhibition of erythrocyte glutathione reductase. Arch. Biochem. Biophys., 393, 199-206. doi:https://doi.org/10.1006/abbi.2001.2487

[16]. Senturk, M., Kufrevioglu, O.I., Ciftci, M. (2008). Effects of some antibiotics on human erythrocyte glutathione reductase: An in vitro study. J. Enzym. Inhib. Med. Chem. 23, 144-148. doi:https://doi.org/10.1080/14756360701342581

[17]. Senturk, E., Urçar, H., Senturk, M., Yildirim, S., Gul, M., (2016). Bovine liver tissue on glutathione reductase enzyme determination of effects of thiamine, tyrosine, dopamine and adrenaline. Acta Physiol., 218, 58.

[18]. Dalmizrak, O., Terali, K., Asuquo, E.B., Ogus, I.H., Ozer, N. (2019). The relevance of glutathione reductase inhibition by fluoxetine to human health and disease: Insights derived from a combined kinetic and docking study. Protein J., 38, 515-524. doi:10.1007/s10930-019-09834-7

[19]. Cakmak, R., Durdagi, S., Ekinci, D., Senturk, M., Topal, G. (2011). Design, synthesis and biological evaluation of novel nitroaromatic compounds as potent glutathione reductase 
inhibitors. Bioorg Med Chem Lett., 21, 5398-5402. doi:https://doi.org/10.1016/j.ejmech. 2009.03.006

[20]. Couto, N., Wood, J., Barber, J. (2016). The role of glutathione reductase and related enzymes on cellular redox homoeostasis network. Free Rad. Biol. Med., 95, 27-42. doi:http://dx.doi.org/10.1016/j.freeradbiomed.2016.02.028

[21]. Benhar, M., Shytaj, I.L., Stamler, J.S., Savarino, A. (2016). Dual targeting of the thioredoxin and glutathione systems in cancer and HIV. J. Clin. Invest., 126, 1630-1639. doi:10.1172/JCI85339 